\title{
A DINÂMICA TERRITORIAL DA EXPANSÃO DO AGRONEGÓCIO SUCROALCOOLEIRO: CONTRIBUIÇÕES TEÓRICAS PARA A ATUAÇÃO DOS MOVIMENTOS SOCIAIS
}

\author{
DINÁMICA TERRITORIAL DE LA EXPANSIÓN DEL AGRONEGOCIO \\ SUCROALCOHOLERO: APORTES TEÓRICOS PARA LA ACTUACIÓN DE \\ LOS MOVIMIENTOS SOCIALES
}

\section{DYNAMICS OF THE TERRITORIAL EXPANSION OF SUCROETHANOL AGRIBUSINESS: THEORETICAL CONTRIBUTIONS TO THE ACTUATION OF SOCIAL MOVEMENTS}

\author{
Marcos Antonio de Souza \\ Mestrando em Geografia pela Universidade Estadual de Londrina \\ geomarcos86@yahoo.com.br
}

\begin{abstract}
Resumo: Partindo-se da premissa de que a crescente expansão do agronegócio sucroalcooleiro após a década de 1970 provocou uma série de impactos socioambientais no espaço agrário brasileiro, a perspectiva de uma expansão ainda maior pela atual conjuntura nacional e internacional aponta para uma proporcional intensificação desses impactos. Assim, na medida em que o agronegócio canavieiro se expande pelo país, ocorreria um aumento proporcional da concentração fundiária, das disputas territoriais com a produção agroalimentária, além da superexploração da força de trabalho empregada nos canaviais. Portanto, o governo brasileiro engendrou em 2009 o Zoneamento Agroecológico da Cana-de-Açúcar, cujo objetivo seria ordenar a produção canavieira no território brasileiro, de modo a se converter em um instrumento capaz de demonstrar à opinião pública nacional e internacional a pretensa sustentabilidade do agronegócio sucroalcooleiro nacional. Nesse contexto, o objetivo deste artigo é analisar o zoneamento implementado pelo governo federal sob a ótica da lógica de localização geográfica do agronegócio sucroalcooleiro, orientada pelo auferimento da renda da terra, demonstrando que esta política de ordenamento territorial não conseguirá mitigar os impactos socioambientais inerentes a produção desse agrocombustível sob os moldes do agronegócio.
\end{abstract}

Palavras-chaves: agronegócio sucroalcooleiro, zoneamento agroecológico, renda da terra, impactos socioambientais, disputas territoriais.

Resumén: Basado en la premisa de que la creciente expansión del agronegocio sucroalcoholero después de la década de 1970 llevó a una serie de impactos socioambientales en el espacio agrário brasileño, la perspectiva de una expansión aún mayor por la actual conyuntura nacional y internacional apunta para uma proporcional intensificación de esos impactos. Así, a la medida en que el agronegócio cañero se expande por el país, se aumentaria proporcionalmente la concentración fundiária, las diputas territoriales con la producción agroalimentária, sin contar con la superexplotación de la fuerza de trabajo empleada en los cañaverales. Por lo tanto, el gobierno brasileño engendró en el 2009 el Zoneamiento Agroecológico de la Caña de 
Azúcar, cuyo objetivo sería reordenar la producción cañera en el território brasileño, de forma a se convertir en un instrumento capaz de demonstrar a la opinión pública nacional y internacional la pretensa sostenibilidad del agronegocio sucroalcoholero nacional. En ese contexto,lo objectivo de ese artículo es analizar el zoneamiento implementado por el gobierno brasileño bajo la optica de la lógica de la localización geográfica del agronegocio sucroalcoholero, orientada por la renta de la tierra, demonstrando que esa política pública no conseguirá mitigar los impactos socioambientales inherentes a la producción de esse agrocombustible bajo los moldes del agronegocio.

Palavras claves: agronegocio sucroalcoholero, zoneamiento agroecologico, renta de la tierra, impactos socioambientales, disputas territoriales.

\begin{abstract}
Based on the premise that the growing expansion of sugarcane agribusiness after the 1970s led to a series of social and environmental impacts in the agrarian space of Brazil, the prospect of a further expansion by the current national and international juncture, points to a proportional intensification of these impacts. Insofar as the sugar cane agribusiness expands across the country, there would be a proportional increase in land concentration, territorial disputes with agro-food production, as well as exploitation of the workforce employed in the fields. Therefore, the Brazilian government in 2009 engineered the Agroecological Zoning of Sugarcane, whose goal would be to organize the sugarcane production in the Brazilian territory, in order to become an instrument capable of showing to the national and international public the alleged sustainability of the national sugarcane agribusiness. In this context, the aim of this paper is to analyze the zoning implemented by the Federal Government from the perspective of the logic of geographical location of the sugarcane agribusiness, driven by the ground rent, showing that spatial policy cannot mitigate the environmental impacts inherent in agrofuel production in the agribusiness way of production.
\end{abstract}

Keywords: sugarcane agribusiness, agroecological zoning, environmental impacts, ground rent, territorial disputes.

\title{
Apresentação
}

Nas últimas três décadas o espaço agrário brasileiro vem sendo cenário de uma voraz expansão da cultura da cana-de-açúcar, motivada primeiramente pela criação do Próalcool na década de 1970, e atualmente impulsionada pela nova geopolítica energética internacional empreendida principalmente pelos Estados Unidos, pela União Européia e demais paises ditos "desenvolvidos", que objetivam reduzir a dependência em relação ao petróleo, mediante a possibilidade de incorporação do etanol à sua matriz energética. 
Não obstante outros fatores que intensificam esse processo de expansão não podem ser esquecidos, como a consolidação de um crescente mercado interno de carros flex e uma valorização no preço do açúcar no mercado internacional.

Para se ter uma idéia desta expansão, do ano de 1979, quando se inicia a produção em larga escala de automóveis movidos a etanol no Brasil, até 2006, houve um incremento de mais de $240 \%$ na área plantada de cana-de-açúcar, passando de 2,39 milhões de ha para 8,14 milhões de hectares na safra 2008/2009. (MAPA, 2009: 10).

O fato é que, muitos estudiosos da questão agrária têm apontado que a expansão do agronegócio sucroenergético tem provocado uma série de impactos no espaço agrário brasileiro, mais especificamente a concentração fundiária, a superexploração da força de trabalho e as disputas territoriais entre a cana-de-açúcar e os cultivos alimentares. Soma-se a isso a possibilidade de severos impactos ambientais caso esta cultura territorializasse (direta ou indiretamente, conforme será abordado posteriormente) porções espaciais geograficamente localizadas em ecossistemas bastante ameaçados, como é o caso do Pantanal mato-grossense e a Amazônia.

Nesse contexto, o Estado brasileiro engendrou em 2009 o ZAE Zoneamento Agroecológico da Cana-de-Açúcar -, com o objetivo de melhorar a imagem do agronegócio sucroalcooleiro brasileiro no exterior através do ordenamento territorial, que supostamente daria sustentabilidade a esta produção.

Assim, o objetivo deste artigo é analisar este zoneamento agroecológico no âmbito da lógica de localização geográfica do agronegócio sucroalcooleiro, visando ratificar a tese de que, mesmo com a implementação desta política pública, a expansão canavieira não estará isenta dos impactos socioambientais inerentes a sua própria dinâmica territorial.

Não obstante, pretende-se ainda fornecer subsídios teóricos para a atuação dos movimentos sociais que lutam pela construção da soberania alimentar, pelo fim do latifúndio e da superexploração dos trabalhadores e, sobretudo, pela construção de uma alternativa produtiva que suplante o agronegócio predatório e insustentável socioambientalmente. 


\section{Algumas considerações acerca dos impactos do agronegócio sucroalcooleiro no Brasil}

Desde 1970, o agronegócio sucroalcooleiro brasileiro sofreu um aumento vertiginoso na sua expansão, trazendo consigo uma série de impactos sociambientais. Enquanto o agronegócio sucroenergético expandiu seus territórios sob várias latitudes da geografia brasileira, houve uma considerável retração das áreas destinadas à produção de alimentos. De acordo com o IBGE (2008), enquanto a cana-de-açúcar sofreu um aumento de pouco mais de 44\% na área cultivada entre os anos de $1990 \mathrm{e}$ 2007, arroz, feijão e batata sofreram uma retração de $24,9 \%, 8,9 \%$ e $9,4 \%$ respectivamente, sendo que, nas regiões em que se encontram as porções espaciais territorializadas pelo agronegócio sucroalcooleiro, essa retração foi ainda maior, como atesta Oliveira (2008):

O avanço de um, reflete inevitavelmente no recuo dos outros. Daí a crítica radical de Jean Ziegler [...] que classificou o etanol como "crime contra a humanidade". A área plantada de cana - de- açúcar na última safra chegou perto de 7 milhões de hectares, e em São Paulo, onde se concentra mais de $50 \%$ do total, já ocupa a quase totalidade dos solos mais férteis existentes [...] Os dados do IBGE entre 1990 e 2006, revelam a redução da produção de alimentos imposta pela expansão da área plantada de cana-de-açúcar, que cresceu nesse período mais de 2,7 milhões de hectares.Tomando-se os municípios que tiveram a expansão de mais de 500 hectares de cana no período, se verifica que neles, ocorreu a redução de 261 mil hectares de feijão e 340 mil hectares de arroz. Esta área reduzida poderia produzir 400 mil toneladas de feijão, ou seja, $12 \%$ da produção nacional e 1 milhão de toneladas de arroz, o que equivale a $9 \%$ do total do país. Além disso, reduziram-se nesses municípios a produção de 400 mil litros de leite e mais de 4,5 milhões de cabeças de gado bovino.

Nessa mesma vertente, Souza (2008:60) aponta que nas mesorregiões paranaenses (Norte e Noroeste paranaense) que concentram mais de 90\% da cana-deaçúcar cultivada no estado, que é o segundo maior produtor nacional, houve um reordenamento territorial que retrata bastante essas disputas territoriais entre a cana-deaçúcar e a produção de alimentos.

Na década de 1980 as culturas de arroz, feijão e cana-de-açúcar ocupavam juntas cerca de 507 mil hectares (IPARDES, 2008), dos quais 89,9\% estavam dedicadas ao cultivo de arroz e feijão, sendo que a cana ocupava apenas 10,1\% desta área.. Com o avanço da monocultura canavieira na década de 1980, ocorreu uma inversão radical no 
espaço agrário setentrional do Paraná. Em 2006, estas três culturas ocupavam cerca de 535 mil hectares, sendo que a cana-de-açúcar passa a ocupar agora 73,7\% desta área, enquanto arroz e feijão dividem $26,3 \%$ desta porção espacial.

A partir dessas duas interlocuções, fica evidente o exposto por Prado Júnior (1981: 31), ao se referir que [...] a grande exploração do tipo comercial [...] tende, quando a conjuntura lhe é favorável, a se expandir e absorver o máximo de terra agricultáveis, eliminando lavouras independentes, [...], bem como suas culturas [...].

Paralelamente a estas disputas territoriais, há ainda a constatação de outros impactos, como é o caso da concentração fundiária e da superexploração da força de trabalho.

Com relação à concentração fundiária, dados do Alcopar (2008: 58) apontam que enquanto na década de 1980, uma unidade agroindustrial no Paraná concentrava em média cerca de 6 mil hectares, em 2006, o tamanho médio cultivado por uma agroindústria canavieira chegava a mais de 16 mil hectares, o que sugere um aumento de cerca de $270 \%$ na concentração fundiária pelo agronegócio sucroenergético.

Por outro lado, a superexploração da força de trabalho dos cortadores de cana emerge como uma das mais vergonhosas espoliações da atualidade, no âmbito da contradição entre a opulência e rentabilidade deste agronegócio frente as precárias condições materiais de existência desses trabalhadores, não raro as vezes, comparados às dos escravos do período colonial.

Submetidos a todo tipo de exploração, centenas de milhares de "bóias-frias" enfrentam cotidianamente uma degradante jornada de trabalho, bastante evidente na exposição de Alves (2006: 93-98):

Um trabalhador que corte 6 toneladas de cana, num talhão de 200 metros de comprimento por 8,5 metros de largura, caminha durante o dia uma distancia de aproximadamente 4.400 metros despende aproximadamente 50 golpes com o podão para cortar um feixe de cana, o que equivale a 183.150 golpes no dia. [...] Além de andar e golpear a cana, o trabalhador tem que a cada $30 \mathrm{~cm}$ se abaixar e se torcer para abraçar e golpear a cana bem rente ao solo e levantar-se para golpeá-la por cima. Além disso, ele ainda amontoa vários feixes de cana cortados em uma linha e os transporta até a linha central. Isto significa que ele não apenas anda 4.400 metros por dia, mas carrega em seus braços, 6 toneladas de cana, com um peso equivalente a 15 $\mathrm{Kg}$, a uma distancia que varia de 1,5 a 3 metros

Além disso, estes cortadores de cana realizam quase quarenta mil entorses torácicas para golpear a cana, sem contar que estes perdem mais de 8 litros d'agua por 
dia durante a execução do seu trabalho. Não obstante, vários desmaios e até mesmo mortes por exaustão física são atribuídos a essa condição degradante de trabalho que os obriga a aumentar a sua produtividade mediante o mecanismo de pagamento por produção. Isso sem contar as flagrantes violações aos direitos trabalhistas, como pagamento indevido ao trabalhador e até mesmo situações de trabalho escravo em vários canaviais do país.

Ora, isto nos sugere que se está diante de um processo de superexploração dos cortadores de cana, visto que sua manutenção em tempos de modernas técnicas agrícolas no campo brasileiro somente se explica pelo fato desta ser mais rentável ao agroindustrial.

Paradoxalmente, a despeito da existência de máquinas sofisticadas, aptas a substituírem de 80 a 100 homens no corte da cana, essa modalidade de trabalho subsiste, o que exige que se fique atento à lógica subjacente de que "quanto mais baixo os salários, tanto mais difícil a introdução de máquinas [...] no campo os salários são [...] muito inferiores aos da cidade. Por conseguinte, é aí menor a tendência a substituir-se a força de trabalho humano pela máquina." (KAUTSKY, 1980: 60).

Aliás, no Brasil os êxitos comerciais do agronegócio se devem essencialmente ao binômio: concentração fundiária e abundância de força de trabalho (PRADO JR, 1981: 48-50). Daí o sentido da expulsão retratado anteriormente, para o auferimento de uma maior renda de terra, combinado à intensificação da apropriação da mais-valia que, juntas, propiciam maior margem de lucros ao empresário rural. No caso específico do agronegócio canavieiro, essa dupla fonte de receitas é drenada por um único agente, que é o agroindustrial. (OLIVEIRA, 2004: 42).

Há assim uma flagrante contradição, somente explicada no âmbito da lógica do desenvolvimento capitalista. Qual o sentido da crescente precarização das relações de trabalho, em um contexto de elevados rendimentos auferidos pelo agronegócio canavieiro?

Eis a fórmula da acumulação tão bem explicitada pela teoria do valor trabalho, num contexto em que mantendo baixo o preço pago pela tonelada ou do metro de cana cortada obriga o cortador de cana a intensificar o seu trabalho. Isso pode ser atestado mediante ao fato de que a produtividade média do cortador de cana em cinco décadas aumentou cerca de 300\%, passando de 3 toneladas na década de 1950 para aproximadamente 12 no final dos anos de 1990. (ALVES, 2006: 92). 
Não obstante aos impactos anteriormente citados, há ainda a possibilidade da expansão do agronegócio sucroalcooleiro provocar sérios danos a ecossistemas já bastante ameaçados, como o Pantanal mato-grossense e a Amazônia, principalmente a partir da reterritorialização de culturas que deram lugar a cana-de-açúcar no âmbito das disputas territoriais, conforme será abordado posteriormente.

\section{O Zoneamento Agroecológico da Cana-de-Açúcar versus a dinâmica territorial do agronegócio sucroalcooleiro}

Conforme foi abordado anteriormente, a expansão da monocultura canavieira nas últimas décadas se processou acompanhada de uma série de impactos socioambientais inerentes a forma pela qual o agronegócio sucroalcooleiro se territorializou no país, orientado apenas pela racionalidade econômica capitalista, tendo em vista a inexistência de marcos regulatórios por parte do Estado brasileiro com o objetivo de disciplinar o uso e a ocupação do solo agrícola no país.

Paralelamente às constatações desses impactos, que refletem a insustentabilidade da produção de agrocombustíveis pelo agronegócio, emergem no contexto nacional e até mesmo internacional, severas críticas à produção do etanol, a ponto de Jean Ziegler (então relator especial da ONU pelo direito à alimentação) classificar a expansão do agronegócio sucroenergético como "crime contra a humanidade". (OLIVEIRA, 2008).

No entanto, com a criação de uma conjuntura internacional favorável a transformação do etanol na mais nova commodity do agronegócio brasileiro, somada aos bons preços do açúcar no mercado internacional, surgem então perspectivas que apontam para uma expansão da cana-de-açúcar, no intuito de suprir a demanda nacional e possivelmente internacional, pelos produtos da canavicultura mercantil.

Nesse contexto, o Estado brasileiro lança em setembro de 2009 o ZAE Zoneamento Agroecológico da Cana-de-açúcar para a produção de etanol e açúcar -, através do decreto $\mathrm{n}^{\circ}$. 6.961/2009, que segundo seus idealizadores objetiva "[...] fornecer subsídios técnicos para formulação de políticas públicas visando o ordenamento da expansão e a produção sustentável de cana-de-açúcar no território brasileiro" (EMBRAPA, 2009: 08).

E essa sustentabilidade no processo de expansão do agronegócio canavieiro aparece explicitada de acordo com a Embrapa (2009: 08) como sendo, entre outras 
coisas, a diminuição da competição direta com as áreas produtoras de alimentos, além da produção de etanol ecologicamente limpo.

Para tanto foram excluídas deste zoneamento porções espaciais geograficamente localizadas nos biomas da Amazônia, do Pantanal e da Bacia do Alto Paraguai, terras indígenas, remanescentes florestais, áreas de proteção ambiental, áreas com cobertura vegetal nativa, dunas, mangues, escarpas e afloramentos de rochas, áreas urbanas e de mineração, além das áreas já ocupadas pela cana-de-açúcar. Soma-se a essas exclusões as terras com declividade superior a $12 \%$, tendo em vista a premissa da mecanização no âmbito da proibição da queima dos canaviais para as áreas de expansão.

Dessa forma, o zoneamento concluiu que o país possui cerca de 64,7 milhões de hectares de terras aptas para o cultivo da cana-de-açúcar, das quais 37,2 milhões se encontram ocupadas atualmente por pastagens, sendo que a Embrapa (2009: 07) sustenta que, "estas estimativas demonstram que o país não necessita incorporar áreas novas e com cobertura nativa ao processo produtivo, podendo expandir ainda a área de cultivo com cana-de-açúcar sem afetar diretamente as terras utilizadas para a produção de alimentos".

Ocorre que o zoneamento agroecológico vem apenas ratificar a frente de expansão do agronegócio canavieiro, uma vez que não altera de forma significativa o vetor de expansão, tentando legitimar a sustentabilidade do agronegócio sucroenergético mediante dados quantitativos que ignoram a lógica da localização geográfica baseada no auferimento da renda fundiária que orienta a expansão deste agronegócio.

Isso fica evidente quando o ZAE 2009 aponta que, mesmo sendo o maior produtor e exportador mundial de açúcar, além do segundo maior produtor de etanol, o Brasil ocupa menos de $1 \%$ de sua área territorial na produção do agronegócio canavieiro, e que caso se cumpra a previsão do Ministério da Agricultura da duplicação da produção, este percentual se elevaria ao máximo para apenas $1,7 \%$ das terras.

O fato é que aquilo que parece ser ínfimo como é o caso dos atuais menos de $1 \%$ e os possíveis futuros $1,7 \%$ do território nacional ocupados pelo agronegócio sucroalcooleiro, se agigantam quando se analisa o percentual das terras brasileiras compostas por lavouras, que são ocupadas pela cana-de-açúcar. De acordo com os dados preliminares do Censo Agropecuário de 2006 (IBGE, 2009), as lavouras (temporárias e permanentes) ocupavam em 2006, uma área de 76.697.324 de hectares, dos quais 8,14 milhões de hectares eram cultivados pela cana-de-açúcar, ou seja, mais de $10 \%$ das terras utilizadas pela agricultura no Brasil. E, se concretizar o aumento 
projetado pelo zoneamento realizado pela Embrapa (2009), que é de cerca de 70\% na área plantada, poderia se ampliar esse percentual a mais de $20 \%$ dessa área ocupada pelas lavouras no país.

Por outro lado, esta análise que leva em conta tão somente o tamanho territorial do Brasil e não a qualidade das porções espaciais disponíveis para um maior auferimento da renda fundiária, pela combinação convergente de vários fatores que a potencializam, acaba tendo força apenas no âmbito ideológico. Isto porque esta abordagem que prima apenas por valores quantitativos acaba por manter os impactos socioambientais no vetor de expansão da cana, visto que os espaços,

[...] não são igualmente capazes de rentabilizar uma produção. Cada combinação tem sua própria lógica e autoriza formas de ação especificas e agentes econômicos e sociais específicos. Os lugares se distinguiriam pela diferente capacidade de oferecer rentabilidade aos investimentos. Essa rentabilidade é maior ou menor, em virtude das condições locais da ordem técnica [...] e organizacional [...]" (SANTOS, 2006: 247-248).

Essa produtividade espacial ou geográfica de que fala Santos, e que possibilita a extração da renda diferencial fundiária, fica evidente ao se analisar as áreas que foram excluídas do zoneamento, em que o governo federal proibirá o cultivo da cana-de-açúcar. A esse respeito, cumpre salientar que quase a totalidade dessas terras não se enquadram na lógica de alocação geográfica do agronegócio sucroalcooleiro, premissa indispensável para orientar sua expansão, como expressa a Figura 01.

Desta forma pode-se constatar que apenas poucas agroindústrias se encontram geograficamente localizadas nos domínios dos biomas amazônico e pantaneiro, porções espaciais mal localizadas com relação aos potenciais mercados consumidores e aos canais de distribuição para o exterior, numa possibilidade desse agrocombustível vir a compor parte significativa da matriz energética de alguns países desenvolvidos.

Portanto, mesmo a inexistência do zoneamento tornaria pouco provável a expansão canavieira rumo a Amazônia principalmente, devido à própria racionalidade econômica capitalista elucidada por Kautsky (1980: 94-95), que aponta que as primeiras terras a serem cultivadas são aquelas mais acessíveis aos mercados.

Não obstante as condições de acessibilidade ao mais promissor mercado consumidor brasileiro que é a região sudeste, Andrade (1994: 229) elucida que razões de ordem climática podem explicar a inexistência da agroindústria sucroalcooleira na 
Amazônia, visto que a umidade excessiva poderia influir na inviabilidade comercial da produção de açúcar devido à pequena produção de sacarose gerada, se comparada a outras regiões do país.

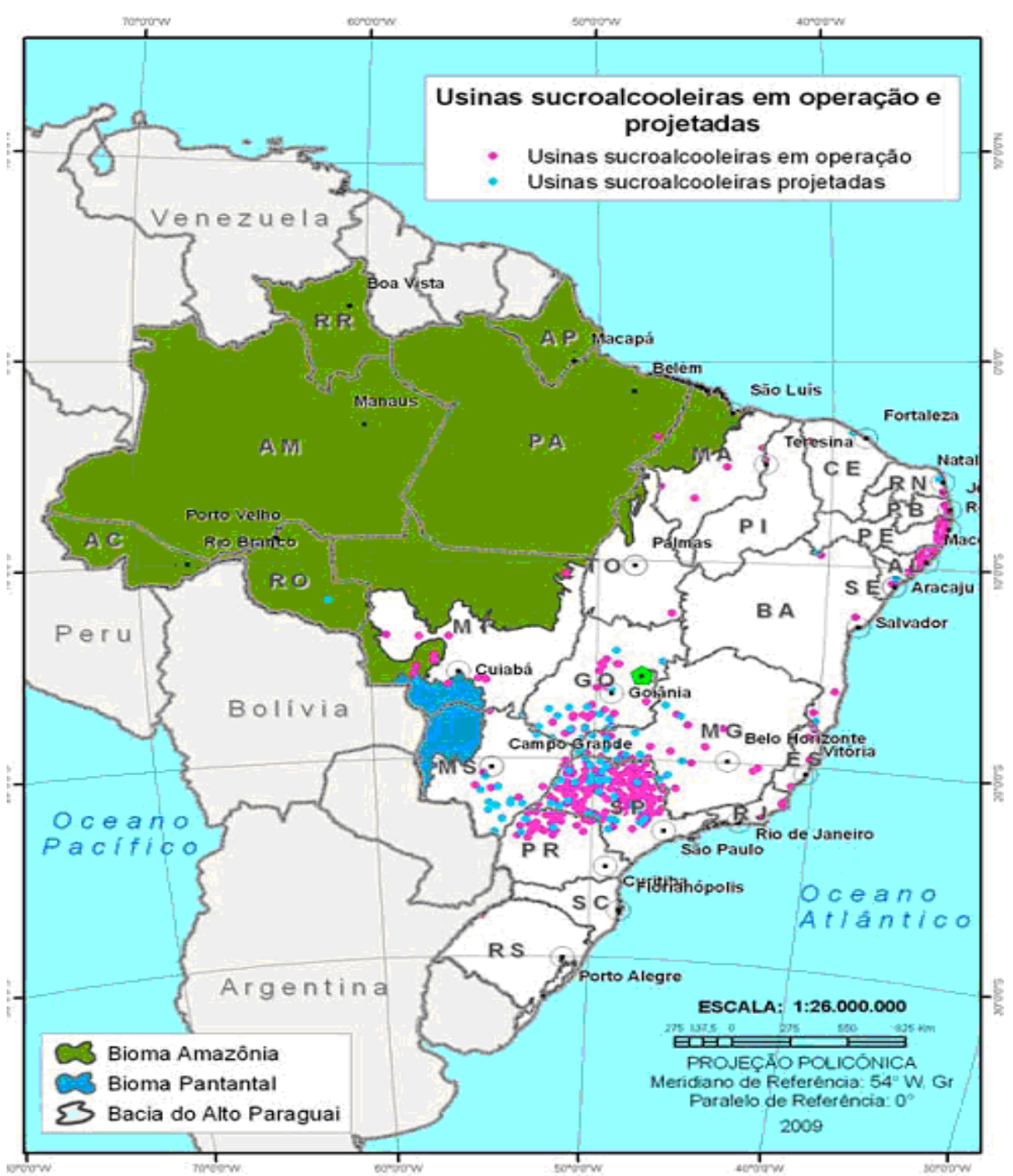

Figura 01: Distribuição espacial das unidades agroindustriais canavieiras pelo Brasil em 2009.

Fonte: Embrapa, 2009.

Ora, isto representa dizer que as terras compreendidas no bioma amazônico seriam potencialmente as últimas em que poderia ocorrer a expansão sucroalcooleira, tendo em vista a abundância de porções espaciais dotadas de uma combinação convergente entre fatores naturais (clima, relevo, fertilidade natural dos solos, etc) e da acessibilidade aos mercados mais importantes, ou seja, com a maior frota de carros movidos a etanol, além da alocação próxima a um sistema de engenharia que garanta a 
fluidez da produção agroindustrial rumo as vias de escoamento da produção para o exterior.

Essas porções espaciais permitiriam aos agroindustriais desse setor auferir uma maior renda fundiária, o que orientaria sua expansão sobre essas terras, e não sobre mangues, dunas, escarpas e afloramentos de rochas, ou sobre o bioma amazônico, que não possui sob seus domínios a referida combinação convergente que potencializa a renda diferencial da terra.

É nesse contexto que deve ser compreendido outro debate, o da competição da cana-de-açúcar com as áreas produtoras de alimentos.

Para muitos teóricos, devido às dimensões continentais do território brasileiro, a expansão da monocultura canavieira não produziria um impacto negativo à produção de alimento, tanto que Carvalho (2006: 05) aponta que "sob a ótica da ocupação do espaço físico, [...] a fronteira parece infinita”.

Não obstante, o zoneamento agroecológico implementado pelo governo federal aponta que a expansão de forma sustentável do agronegócio sucroalcooleiro não irá afetar a produção de alimentos.

O fato é que como já foi abordado anteriormente, nada assegura que esse processo irá ser orientado prioritariamente rumo a áreas de pastagens degradadas como faz crer o zoneamento, pelo contrário, as primeiras terras que serão incorporadas a expansão do agronegócio canavieiro são aquelas que são dotadas de uma combinação convergente de vários fatores que potencializem a renda fundiária. E como se pode observar no mapa 01, esta expansão tem se orientado e se concentrado para áreas já inseridas na dinâmica econômica nacional, visto que a região Centro-Sul concentra cerca de $85 \%$ da cana-de-açúcar produzida no país, sendo que somente o estado de São Paulo contribui para quase $60 \%$ da produção nacional. (SOUZA, 2008: 21).

Assim, a lógica que estaria norteando o processo de territorialização da canavicultura está diretamente ligado à disputa pela melhor possibilidade de auferir a maior renda fundiária possível, e isso se define em virtude da melhor localização frente aos mercados, da fertilidade diferencial dos solos, da topografia e demais variáveis que interferem na produtividade das lavouras, entre outros fatores.

Nesse contexto, a disputa da lavoura canavieira por melhor localização tende a reordenar o espaço agrário das regiões já inseridas dinamicamente na economia nacional/internacional, uma vez que sua expansão se dá preferencialmente nas áreas que 
asseguram maior renda da terra, independentemente de se tratar de áreas cultivadas com feijão, trigo, milho, pastagens, soja, mandioca etc.

Cabe ressaltar que de acordo com a Embrapa (2009: 12), dos 64,7 milhões de hectares aptos à expansão do agronegócio sucroenergético, 36,7 milhões já se encontram utilizadas pela agropecuária nas porções espaciais consideradas de alta e média aptidão agrícola. Não obstante em cumprir com os requisitos do ambiente edafoclimático, estas áreas que obviamente não se encontram incultas, ocupam uma privilegiada porção do espaço geográfico com relação aos potenciais mercados consumidores.

E o agroindustrial canavieiro não irá medir esforços para conseguir a melhor localização geográfica possível, assim como os demais empresários do agronegócio.

Muitos poderão, por exemplo, refutar esta tese, argumentando que o alto grau de desenvolvimento cientifico e biotecnológico pode " criar" condições especiais , como a correção de diversos tipos de solos, criação de variedades de cana-de-açúcar que se adaptam aos mais diversos domínios pedológicos e climáticos do país .

Não que isto seja uma inverdade, porque de fato não o é. Ocorre que o agroindustrial busca num primeiro momento territorializar as porções de espaço geográfico que naturalmente possuem vantagens comparativas superiores às demais localidades, a fim de evitar maiores investimentos e, por sua vez, redução da margem de lucros.

Ora, que capitalista irá imobilizar parte de seu capital na correção de solos, ou em pesquisa e tecnologia para o desenvolvimento de uma variedade de cana específica, quando dispõe de ambientes que dispensam tais investimentos?

Isso só faria sentido quando se esgotarem as possibilidades da melhor localização natural. Enquanto isso não ocorre, a disputa segue a lógica da territorialização das porções do espaço geográfico que permitem uma maior renda fundiária.

Segundo as leis da física, dois corpos não podem ocupar o mesmo lugar no espaço, de modo que as áreas ocupadas por feijão, pecuária, trigo, soja, algodão etc serão objeto de interesse dos agroindustriais canavieiros, quando localizadas nos vetores de expansão da cana-de-açúcar.

Os mapas 02 e a figura 03 apresentam uma dimensão dessas disputas territoriais ao apontar o atual uso dos solos nas áreas aptas para expansão do agronegócio sucroalcooleiro, senão vejamos: 


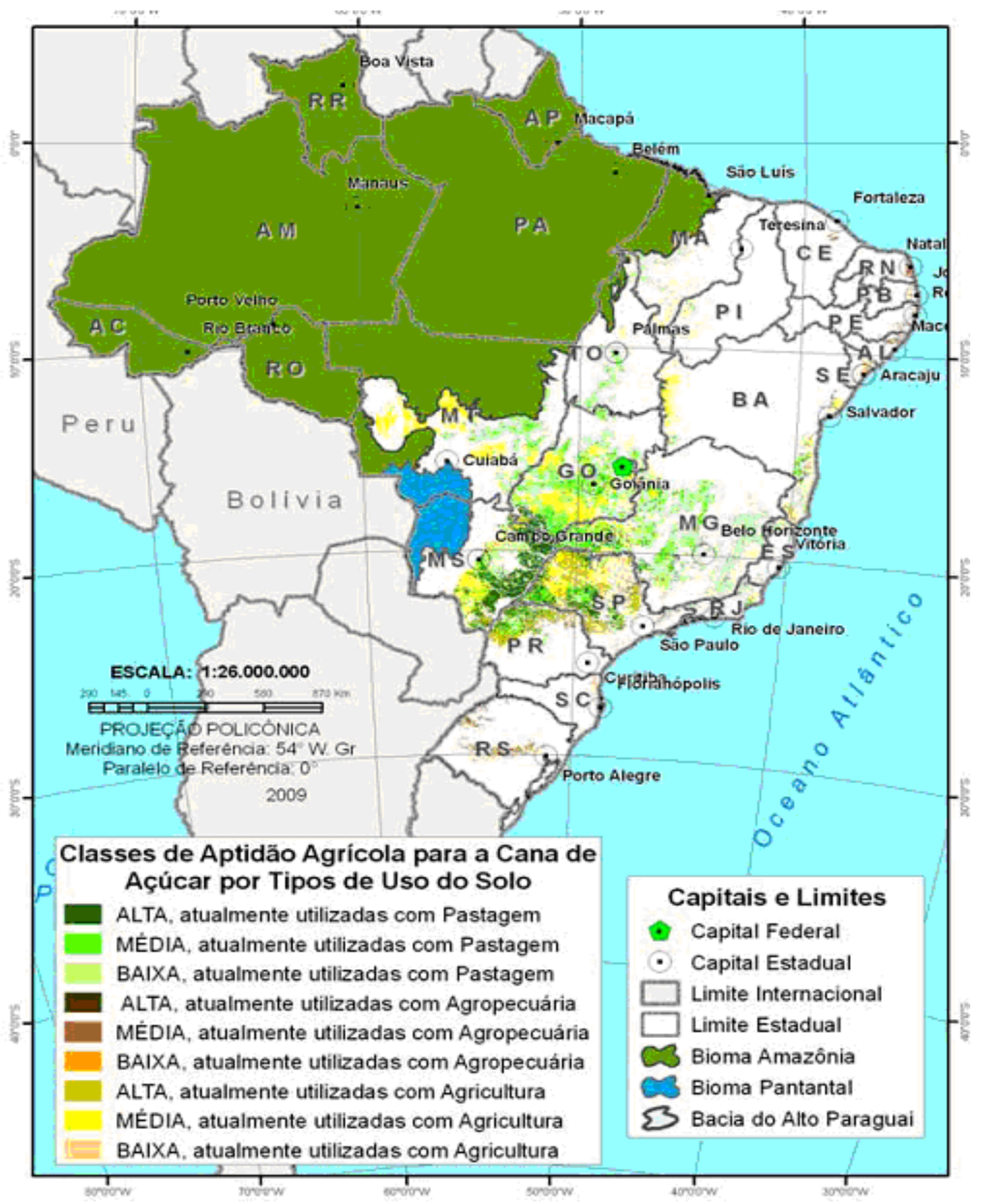

Figura 02: Zoneamento agroecológico da cana-de-açúcar - usos da terra Fonte: Embrapa, 2009. 


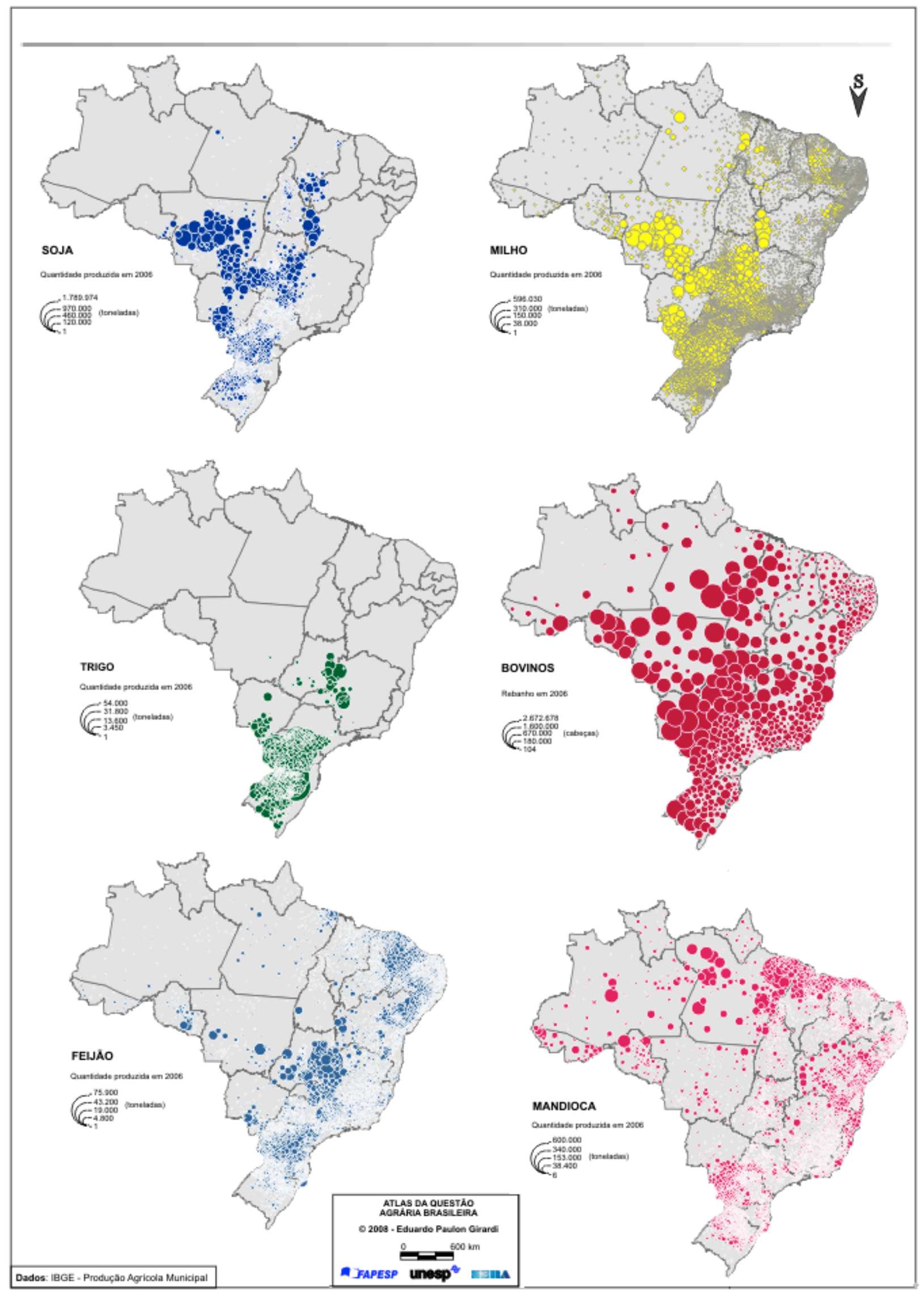

Figura 03: Territorialização de culturas selecionadas no espaço agrário brasileiro Fonte: Atlas da Questão Agrária Brasileira, 2009. 
O dinamismo econômico e a produtividade espacial apontada por Santos (2006: 247-248), encontrados na região Centro-sul, faz com que as porções espaciais aí localizadas sejam as mais cobiçadas pelo agronegócio, e desta forma sejam as áreas prioritárias não só para a expansão da cana, mas também de várias outras culturas, tanto produzidas no âmbito da agricultura familiar, pelo campesinato ou até mesmo pelo agronegócio.

Nesse contexto não se pode justificar a sustentabilidade do agronegócio sucroalcooleiro em argumentos baseados em dados quantitativos que apontam a existência de milhões de hectares a se expandir, mas sim na qualidade destas porções espaciais disponíveis.

Assim, comparando o mapa da figura 02, que apresenta as áreas com aptidão para o agronegócio canavieiro, com os mapas da figura 03, que traz a territorialização de algumas culturas agrícolas no Brasil, pode-se constatar certa convergência entre os fatores locacionais de várias destas culturas, dada a concentração geográfica das mesmas na região Centro-Sul brasileira, considerada a área mais cobiçada pelo agronegócio nacional.

Desta forma intensas disputas territoriais poderão ocorrer nesta porção privilegiada do espaço geográfico brasileiro, orientadas, sobretudo pela rentabilidade das culturas, gerando um intenso processo de territorialização-desterrritorialização e reterritorialização, quando o milho, o trigo, o feijão, a soja ou as pastagens encontraremse nos vetores prioritários da expansão da cana

E isto irá ocorrer independentemente da existência de milhões de hectares vagos ou subaproveitados pela pecuária, mas que não dispõem de vantagens locacionais para a viabilidade comercial e econômica do agronegócio sucroalcooleiro.

Levando-se em conta que a única racionalidade que conta é a racionalidade econômica capitalista, ganha esta disputa por território aquela atividade que apresentar as melhores possibilidades de extração de renda fundiária para um mesmo solo.

E é esta mesma lógica de territorialização que atua na expansão da fronteira agrícola rumo a biomas e ecossistemas fortemente ameaçados, como a Amazônia e o Cerrado, por exemplo .

Os defensores do agronegócio afirmam ser ínfima a participação da produção de cana na Amazônia, ignorando propositalmente o fato de que atualmente não existe o interesse, muito menos a necessidade de se expandir rumo a esta porção 
territorial, tendo em vista os próprios fatores locacionais tratados anteriormente, que não refletem na atualidade na melhor localização possível

Daí a inconsistência da política de zoneamento apresentada pelo governo federal, que ignora a dinamicidade do processo de territorialização-desterritorializaçãoreterritorialização dos cultivos no espaço agrário brasileiro. As disputas territoriais por essas porções espaciais capazes de garantir uma maior renda fundiária ao agroindustrial, com as áreas produtoras de alimentos, e que se encontram no raio de expansão do agronegócio sucroalcooleiro, provocariam uma desterritorialização das culturas menos rentáveis. Isto, por sua vez, poderia provocar uma reterritorialização destas culturas que foram "engolidas" pela expansão canavieira em áreas periféricas, localizadas na fronteira agrícola em expansão, na Amazônia, por exemplo.

Dessa forma, não se trata de criar mecanismos que ordenem a expansão no sentido de impedir a incorporação de novas áreas, mas sim levar em conta a dinâmica territorial das regiões já inseridas no processo de produção do agronegócio canavieiro, que por sinal foram excluídas do zoneamento. (EMBRAPA. 2009: 08).

Até porque a tendência iniciada com o advento do Proálcool não aponta para uma expansão propriamente dita rumo a terras incultas ou ao bioma amazônico, por exemplo, mas sim sugere um processo de concentração nas porções espaciais já inseridas à dinâmica econômica brasileira, conforme já destacado anteriormente.

E é justamente nos domínios desta concentração espacial que ocorrem a maioria das disputas territoriais, constatação esta que deveria ser contemplada no zoneamento proposto pelo governo brasileiro.

Diante dessas evidencias, a questão das disputas territoriais não pode ser resolvidas mediante o pretenso ordenamento territorial de uma única cultura. Não haverá, todavia, mecanismos que assegurem que uma quantidade estratégica de terras deva ser destinada a produção de arroz ou feijão, por exemplo, no âmbito da produção da soberania alimentar no Brasil.

O zoneamento somente demarca áreas a se expandir prioritariamente, mas estas já estão inseridas na porção espacial mais dinâmica e mais cobiçada pelo agronegócio, do ponto de vista do auferimento da maior renda territorial, o que incitará as disputas territoriais entre o agronegócio sucroalcooleiro e as demais culturas.

Sem levar em consideração essas premissas, não se poderá assegurar que a expansão da monocultura canavieira não impactará negativamente a produção de 
alimentos no âmbito das disputas territoriais, e tampouco haverá a sustentabilidade ecológica propalada pelos idealizadores deste zoneamento.

É nesse contexto da busca e da disputa pela melhor localização geográfica possível num determinado período histórico, que se explica todo o rearranjo territorial do espaço agrário brasileiro, em que monopolizar as porções do espaço geográfico dotadas de uma combinação convergente entre os vários fatores de localização, significa a possibilidade real de se extrair uma maior renda fundiária.

E, ao desfrutar da melhor localização geográfica, classes ou frações de classe passam a auferir renda em patamares diferenciais, além de controlar a terra, os recursos naturais, a força de trabalho, as políticas públicas etc, numa demonstração incontestável de controle e capacidade de ordenamento territorial conforme interesses privados, que ficaram intactos com a aprovação desse zoneamento.

Por outro lado, apesar de o documento assegurar que o Ministério da Agricultura criará mecanismos que orientem “[...] a expansão da produção da cana a fim de evitar qualquer risco à produção de alimentos ou à segurança alimentar", o ZAE não aponta especificamente como isso se dará. Já o decreto $\mathrm{n}^{\mathrm{o}}$. 6.961/2009 afirma no seu art. $3^{\text {o }}$ que "o Conselho Monetário Nacional estabelecerá as condições, critérios e vedações para a concessão de crédito rural e agroindustrial à produção e industrialização de canade-açúcar, açúcar e biocombustíveis", mas não elucida quais serão estas condições e estes critérios, que já entrariam em vigor na safra 2009/2010.

Cabe ressaltar ainda que não se pode falar na produção sustentável do agronegócio canavieiro, sem antes eliminar os mecanismos de exploração do cortador de cana, e muito menos sem planejar estratégias de reinserção destes no mercado de trabalho uma vez se materialize a tendência da mecanização do corte.

Nesse aspecto o zoneamento é bastante vago. Apesar de o documento expressar que foi levado em conta aspectos econômicos e sociais na sua elaboração, o ZAE não explica de que forma ocorrerá o "aumento da ocupação permanente da mãode-obra local, com a substituição da colheita manual pela mecânica", se o que ocorrerá de fato é a diminuição considerável da oferta de trabalho nessas agroindústrias com a adoção de máquinas aptas a eliminar mais de cem postos de trabalhos cada uma. Tampouco explica de que forma ocorrerá a "geração de renda ao longo do ano durante o ciclo da cultura" (EMBRAPA, 2009: p.09), diante dessas constatações. 
Ora, esta afirmação desconsidera as centenas de milhares de cortadores de cana que perderão seus postos de trabalhos, mesmo que temporários, dos quais a maioria absoluta sequer serão recrutadas para os treinamentos de qualificação para a mecanização da colheita, tendo em vista, por exemplo, sua baixa escolaridade e a própria competição com a máquina, como aponta $\operatorname{Souza}(2008$, p.97).

O documento mais específico que trata das condições dos cortadores de cana é o chamado "Compromisso Nacional para Aperfeiçoar as Condições de Trabalho na Cana-de-açúcar", lançado em 2009 pelo governo federal com adesão voluntária das agroindústrias, e que objetiva aplicar boas práticas trabalhistas no corte da cana. Não obstante, esse documento não elimina a forma de pagamento por produção, mecanismo que induz a um constante aumento da produtividade mediante o rebaixamento do preço da tonelada ou do metro de cana cortada, além de não regular sequer um tempo de descanso remunerado para as refeições dos cortadores de cana.

E, finalmente, quando se analisa a sustentabilidade do discurso da produção do etanol no âmbito da energia limpa, uma pesquisa do IEMA - Instituto de Energia e de Meio Ambiente -, aponta que a emissão de gases poluentes por um carro flex é maior com álcool/etanol do que com gasolina:

É muito provável que quem tenha um carro com motor flex polua menos ao usar gasolina do que álcool. [...] os carros flex que usam álcool emitem mais monóxido de carbono [...] do que os que utilizam gasolina [...] Em relação aos aldeídos, que ajudam na formação do ozônio - principal preocupação em áreas urbanas [...] o carro a álcool em geral, emite oito vezes mais. $\mathrm{Na}$ emissão de hidrocarbonetos é grande a desvantagem do álcool no Celta, no novo Gol e no Fiesta [...] $\mathrm{Na}$ avaliação dos óxidos de nitrogênio, dos seis modelos avaliados, somente no novo Gol o álcool era menos poluente.

(BALAZINA, 2009: A22).

Portanto, conforme podemos observar, ainda se está longe de se vislumbrar a possibilidade da produção sustentável dos agrocombustiveis no país, num contexto em que as políticas públicas engendradas pelo governo brasileiro atuam no sentido de favorecer o agronegócio em detrimento da soberania alimentar, das precárias condições sociais dos cortadores de cana, da concentração fundiária e, conseqüentemente, de renda. 


\section{Considerações Finais}

Conforme foi abordado ao longo deste artigo, o zoneamento agroecológico para a produção de cana de açúcar, o ZAE, não irá mitigar os principais impactos socioambientais inerentes ao agronegócio sucroalcooleiro.

Primeiramente, porque não leva em consideração uma reserva de terras estratégicas para a produção da demanda interna de alimentos, no âmbito da soberania alimentar, ficando esta exclusivamente sob a regulação dos mecanismos de mercado capitalista.

O principal argumento dos defensores da expansão do agronegócio canavieiro, que é a grandeza territorial do Brasil, não pode justificar essa despreocupação, tendo em vista que as disputas territoriais entre esse agronegócio e a produção de alimentos, dão-se no âmbito das porções espaciais atualmente inseridas na dinâmica econômica nacional, orientadas pela rentabilidade.

Isso fica bastante evidente ao se constatar que, nas ultimas quatro décadas, a produção canavieira apresentou uma tendência de concentração espacial sob áreas produtivas, o que sugere uma expulsão das culturas menos rentáveis de suas antigas territorialidades.

E a principal explicação para esse fenômeno é que a cana, como qualquer outra atividade econômica, busca territorializar porções do espaço geográfico dotadas de uma combinação convergente de uma série de atributos que potencializem um auferimento da maior renda fundiária possível, independente se estas já estejam ocupadas por outras culturas.

Não obstante, nada parece apontar para um compromisso nacional que assegure a soberania alimentar, tendo em vista a própria destinação dos fundos públicos e demais incentivos estatais para a agroexportação.

Por outro lado, as restrições impostas pelo zoneamento para se cultivar cana na Amazônia, por exemplo, não passam de medidas pirotécnicas para exportar uma imagem de sustentabilidade do agronegócio canavieiro ao mais conhecido internacionalmente bioma brasileiro, visto que a lógica da localização geográfica da agroindústria canavieira tornaria improvável a expansão da cana para esta porção espacial. 
Isso fica evidente quando se constata a inexistência de marcos regulatórios de ordenamento territorial - leia-se zoneamento agroecológico com abrangência nacional - para a expansão da soja, das pastagens e de outras culturas no bioma Amazônico. Ora, se a cana territorializa porções espaciais onde antes se cultivavam soja, milho, ou existiam pastagens, não há mecanismos que impeçam estas culturas “engolidas pela cana” se realocarem na Amazônia, por exemplo.

Quanto à "produção de biocombustíveis de forma sustentável e ecologicamente limpa" (EMBRAPA, 2009: 09) o zoneamento não deixa clara a questão dos agrotóxicos pesados utilizados nessa cultura, da degradação dos solos e, quanto ao combustível, este tampouco pode ser rotulado como "limpo", como abordado anteriormente.

Por outro lado nada parece apontar para uma sustentabilidade nas relações sociais de produção entre o cortador de cana e a agroindústria, nem no ZAE ou no chamado "Compromisso Nacional para Aperfeiçoar as Condições de Trabalho na Canade-açúcar", visto que em nenhum destes as demandas históricas são contempladas.

Tampouco se vislumbra qualquer projeção de inserção destes ao mercado de trabalho com a eliminação de centenas de milhares de postos de trabalhos pela tendência de mecanização do corte de cana.

\section{Referências:}

ALCOPAR. Histórico da produção no Paraná. Disponível em: <http://www.alcopar. org.br/estatisticas/hist_prod_pr.htm > Acesso em: 07 abr. 2008.

ALVES, Francisco. Porque morrem os cortadores de cana? Revista Saúde e Sociedade. São Paulo: FSP/USP, v.15, n. 3, p. 90-98, set/dez 2006. Disponível em: $<$ http://www.apsp.org.br/saudesociedade/XV_3/revista\%2015.3_artigo\%2006.p df>. Acesso em: 23 mar. 2008.

ANDRADE, Manuel Correia de. Modernização e pobreza: A expansão da agroindústria canavieira e seu impacto ecológico e social. São Paulo: UNESP, 1994.

BALAZINA, A. Carro flex polui menos com gasolina. O Estado de São Paulo. 17 set. 2009, Caderno A, p.22. 
BRASIL. Ministério da Agricultura, Pecuária e Abastecimento. Departamento da Canade-açúcar e Agroenergia. Produção brasileira de álcool e cana - de açúcar, 2002-2007. Brasília: MAPA, 2008. Disponível em: http://www.agricultura.gov.br/pls/portal/docs/page/mapa/estatisticas/producao/pr od_cana_acucar_alcool_mensal.pdf. Acesso em: 10 mar. 2008.

. Agricultura brasileira em números/anuário 2005. Brasília: MAPA, 2008. Disponível

em: http://www.agricultura.gov.br/pls/portal/docs/page/mapa/estatisticas/agricultura em_numeros_2005/03.02.05_1.xls . Acesso em: 20 fev. 2008.

. Anuário Estatístico da Agroenergia. Brasília: MAPA, 2009. Disponível em $<$ http://www.agricultura.gov.br/>. Acesso em 20 jun. 2009.

Levantamento sistemático da produção agrícola. Rio de Janeiro: IBGE, 2008 .

Disponível em http://www.ibge.gov.br/home/estatistica/indicadores/agropecuaria/lspa/lspa_200 810_4.shtm>. Acesso em 20 jul. 2008.

.Resultados preliminares do Censo Agropecuário de 2006. Rio de |Janeiro, 2009.

Disponível em

http://www.ibge.gov.br/home/presidencia/noticias/noticia_visualiza.php?id_noti cia $=1064 \&$ id_pagina=1> Acesso em 05 nov. 2009.

Zoneamento Agroecológico da Cana-de-Açúcar. Brasília: EMBRAPA, 2009.

CARVALHO, Glauco Rodrigues. O Setor sucroalcooleiro em Perspectiva. Revista Conjuntura Agropecuária: Sucroalcooleira. Campinas: EMBRAPA, mar. 2006. Disponível em: $<$ http://www.cnpm.embrapa.br/conjuntura/0603_Sucroalcooleiro. pdf $>$.Acesso em: 23 mar. 2008.

GIRARDI, E.P. Atlas da questão agrária brasileira. Presidente Prudente: UNESP, 2008. Disponível em < http://www4.fct.unesp.br/nera/atlas/ > Acesso em 12 jul.2009.

IPARDES. Base de dados do estado. Disponível em: $<\mathrm{http}$ ://www.ipardes.gov.br/imp/index.php>. Acesso em: 12 maio 2008.

KAUTSKY, Karl. A questão agrária. São Paulo: Proposta, 1980.

OLIVEIRA, A.U. Geografia agrária: perspectivas no inicio do século XXI. In: OLIVEIRA, A.U.; MARQUES, I.M. (Orgs). O campo no século XXI: o 
território de vida, de luta e de construção de justiça social. São Paulo: Casa Amarela, 2004. p. 29-70.

OLIVEIRA, A.U. Agrocombustíveis e produção de alimentos. MST, 23 abr. 2008. Disponível em: $<$ http://www.mst.org.br/mst/pagina.php?cd=5310> Acesso em: Acesso em 20 jun. 2008.

PRADO JÚNIOR, C. A Questão agrária no Brasil. São Paulo: Brasiliense, 1981.

SANTOS, Régis R. A territorialização do capital e as relações camponesas de produção. Campo-Território: Revista de Geografia Agrária. v. 2, n.3, p. 40-54, fev. 2007. Disponível em: <www.campoterritorio.ig.ufu.br/include/getdoc.php? id=134 \&article $=86 \& \bmod \mathrm{e}=\mathrm{pdf}>$. Acesso em: 09 abr. 2008.

SOUZA, Marcos Antonio de. A territorialização do agronegócio canavieiro no norte do Paraná: estudo de caso. 2008. Monografia (Bacharelado em Geografia) Universidade Estadual de Londrina. 